\title{
Efektivitas Fungi Mikoriza Arbuskula Dan Arang Tempurung Kelapa Terhadap Pertumbuhan Bibit Aren Pada Tanah Ultisol
}

\author{
Rike Puspitasari Tamin, Suci Ratna Puri \\ Fakultas Kehutanan, Universitas Jambi, Indonesia \\ Email: rikepuspitasari unja@yahoo.co.id
}

\begin{abstract}
ABSTRAK
Tanaman aren (Arenga pinnata (Wurmb) Merr.) dikenal sangat luas yang memiliki manfaat yang multiguna yaitu sebagai pemenuhan kebutuhan pangan dan berpotensi besar dimanfaatkan sebagai energi alternatif yang dapat diperbaharukan yang ramah lingkungan. Peningkatan ini mengakibatkan eksploitasi aren semakin tinggi, sehingga dikawatirkan akan menyebabkan ketersediaan aren semakin menurun apabila tidak diimbangi dengan adanya budidaya dari aren . Penggunaan Fungi Mikoriza Arbuskula (FMA) dan arang tempurung kelapa pada pembuatan bibit aren diharapkan dapat meningkatkan pertumbuhan yang optimal. Tujuan penelitian ini adalah untuk mempelajari interaksi antara FMA dan arang tempurung kelapa pada tanah ultisol terhadap pertumbuhan bibit aren serta untuk mendapatkan dosis inokulum FMA dan komposisi media terbaik untuk pertumbuhan aren. Penelitian ini menggunakan Rancangan Acak Lengkap (RAL) dengan pola faktorial yang terdiri atas dua perlakuan yaitu dosis FMA dan komposisi media (ultisol dan arang tempurung kelapa) dengan tiga ulangan. Hasil Penelitian menunjukkan pemberian dosis arang tempurung kelapa memberikan pengaruh yang sangat nyata terhadap pertambahan jumlah daun, Pemberian mikoriza memberika pengaruh yang sangat nyata pada variabel persen infeksi akar serta Pemberian dosis arang tempurung kelapa $10 \%$ dan dosis mikoriza $10 \mathrm{~g}$ menunjukkan pengaruh yang lebih baik terhadap pertumbuhan tanaman Aren.
\end{abstract}

Kata Kunci: Aren, FMA, arang tempurung kelapa

\section{PENDAHULUAN}

Tanaman aren (Arenga pinnata (Wurmb) Merr.) dikenal sangat luas yang memiliki manfaat yang multiguna yaitu sebagai pemenuhan kebutuhan pangan dan berpotensi besar dimanfaatkan sebagai energi alternatif yang dapat diperbaharukan yang ramah lingkungan. Aren juga memiliki nilai potensi cukup tinggi karena dapat diolah sebagai bioetanol (Ditjen Perkebunan, 2004; Effendi, 2009; Lempang, 2012). Saat ini pemanfaatan tanaman aren yang bernilai ekonomi tinggi dan sangat diminati oleh masyarakat adalah nira (Akuba, 2004; Rindengan dan Manaroinsong, 2009). Selain memiliki potensi dari seluruh bagian tanamannya, 
tanaman ini juga memiliki daya adaptasi yang baik pada berbagai agroklimat, mulai dari dataran rendah hingga $1400 \mathrm{~m}$ di atas permukaan laut.

Potensi Aren yang sangat tinggi mengakibatkan kebutuhan akan Aren semakin meningkat pula. Peningkatan ini mengakibatkan eksploitasi aren semakin tinggi, sehingga dikawatirkan akan menyebabkan ketersediaan aren semakin menurun apabila tidak diimbangi dengan adanya budidaya dari aren tersebut mengingat tanaman aren ini memiliki umur panen yang cukup panjang (7-12 tahun) (Manaroinsong et al., 2006 dan Setiawan, 2014). Selama ini para pengusaha aren masih menggunakan cara yang konvensional yang belum menerapkan teknik perbanyakan tanaman yang tepat sehingga bibit yang dihasilkan memiliki kualitas yang rendah. Kualitas yang rendah pada bibit inilah menjadi faktor memperlambat masa pindah tanam ke lapangan.

Salah satu faktor yang dapat meningkatkan mutu bibit yaitu media tanam. Ultisol merupakan media tanam yang paling banyak tersedia terutama di Provinsi Jambi. Luas tanah Ultisol 2.036.368 ha atau mencapai 39,93 \% dengan potensi penggunaan lahan untuk pertanian (Pemerintah Provinsi Jambi, 2011). Dalam pemanfaatannnya, terdapat permasalahan yang ditemui pada tanah ini yaitu memiliki $\mathrm{pH}$ yang rendah, kandungan unsur yang sangat rendah, kejenuhan $\mathrm{Al}$ yang tinggi, KTK yang rendah dan kandungan bahan organik yang rendah dengan $\mathrm{C} / \mathrm{N}$ rasio yang tergolong rendah (Subekti et al., 2017), untuk itu sebelum dimanfaatkan, tanah ini harus dilakukan pengolahan yaitu memperbaiki sifat fisik dan biologi tanah dalam hal ini pemanfaatan penggunaaan mikroorganisme dan penambahan penambahan bahan organik tanah.

Mikoriza merupakan salah satu mikroorganisme yang dapat memperbaiki sifat biologi maupun kimia tanah, cendawan ini mampu bersimbiosis dengan semua jenis tanaman. Tanaman yang berasosiasi dengan mikoriza dapat meningkatkan ketahanan tanaman terhadap kekeringan, meningkatkan penyerapan unsur hara, dan membantu tanaman tumbuh dan berkembang dengan cepat (Nurmalasari, 2009). Mikoriza memiliki peran sebagai penambat P di dalam tanah sehingga unsur tersebut dapat tersedia bagi tanaman. Mikoriza memiliki hifa yang mengeluarkan enzim phosphatase yang dapat melepaskan P yang terikat dengan unsur lain sehingga tersedia bagi tanaman (Dewi, 2007).

Selain menggunakan mikoriza, penambahan arang tempurung kelapa mampu meningkatkan pertumbuhan tanaman melalui perbaikan pada sifat fisik dan kimia (Soemeinaboedhy dan Tejowulan, 2007). Perbaikan sifat fisik tanah melalui perbaikan sirkulasi air dan udara di dalam tanah, peningkatan $\mathrm{pH}$, memudahkan terjadinya pembentukan dan peningkatan jumlah spora dari ektomikoriza maupun endomikoriza pada akar tanaman dengan memberikan unsur hara tambahan bagi mikroorganisme serta menjadi tempat berlindung melalui pori-pori yang ada sehingga dapat merangsang pertumbuhan akar serta memberikan habitat yang baik untuk pertumbuhan semai tanaman (Warnock et al., 2007). 


\section{Tujuan Penelitian}

Tujuan penelitian ini adalah untuk menganalisis pengaruh interaksi antara Fungi Mikoriza Arbuskular (FMA) dan arang tempurung kelapa terhadap pertumbuhan aren serta untuk mendapatkan dosis inokulum FMA dan campuran media tanam (tanah ultisol dan arang tempurung) yang terbaik untuk pertumbuhan aren.

\section{Hipotesis Penelitian}

1. Terdapat interaksi antara efektifitas inokulasi FMA dan arang tempurung kelapa terhadap pertumbuhan Aren (Arenga pinnata (Wurmb) Merr.) di pembibitan.

2. Terdapat pengaruh pemberian dosis terbaik inokulasi FMA dan arang tempurung kelapa terhadap pertumbuhan Aren (Arenga pinnata (Wurmb) Merr.) di pembibitan.

3. Pemberian dosis inokulasi FMA $10 \mathrm{~g}$ dan arang tempurung kelapa $10 \%$ memberikan pengaruh terbaik terhadap pertumbuhan Aren di pembibitan.

\section{METODE PENELITIAN}

\section{Tempat dan Waktu Penelitian}

Penelitian ini dilaksanakan selama 6 bulan dari bulan April-Oktober 2020 dan dilaksanakan di lokasi pembibitan dan Laboratorium Silvikultur Jurusan Kehutanan Universitas Jambi.

\section{Bahan dan Alat}

Bahan yang diperlukan dalam penelitian ini adalah benih aren, inokulum FMA yang diperoleh dari Pusat Penelitian dan Pengembangan Hutan Gunung Batu Bogor, arang tempurung kelapa yang dihaluskan dan diayak agar mendapatkan ukuran yang seragam, subsoil, pasir, polybag, trypan blue, gliserin, $\mathrm{KOH}, \mathrm{H}_{2} \mathrm{O}_{2}, \mathrm{H}_{2} \mathrm{SO}_{4}$, $\mathrm{HCL}$, dan aquadest, kaca preparat, cover glass. Penelitan ini menggunakan alat-alat antara lain : paranet 75\%, plastik stek, autoclave, mikroskop, timbangan digital, amplop coklat, kaliper, penggaris, label, amplop coklat, thermohygrometer, cawan petri, gembor, $\mathrm{pH}$ meter, benang, label, spidol permanenet, cangkul, ember, kamera, dan alat tulis.

\section{Rancangan Percobaan}

Penelitian ini menggunakan Rancangan Acak Lengkap (RAL) pola faktorial dengan 2 (dua) faktor yaitu penggunaan dosis FMA dan komposisi media tanam dengan 4 (empat) ulangan. Faktor pertama (dosis FMA) terdiri dari 4 (empat) taraf, antara lain : $\mathrm{m}_{0}=$ kontrol (tanpa FMA); $\mathrm{m}_{1}=5 \mathrm{gr} /$ bibit; $\mathrm{m}_{2}=10 \mathrm{gr} /$ bibit; $\mathrm{m}_{3}=15 \mathrm{gr} / \mathrm{bibit}$. Untuk faktor kedua (media tanam) terdiri dari 3 (tiga) taraf, antara lain : $\mathrm{k}_{0}=$ control 
(tanpa arang tempurung); $\mathrm{k}_{1}=10 \% \mathrm{v} / \mathrm{v}$ arang tempurung dan $\mathrm{k}_{2}=20 \% \mathrm{v} / \mathrm{v}$ arang tempurung

\section{Pelaksanaan Penelitian}

Semai yang digunakan adalah bibit yang berasal dari benih yang telah dikecambahkan. Bibit dicari yang berukuran seragam baik dari tinggi, diameter, maupun jumlah daun. Benih aren sebelum dikecambahkan diberi perlakuan perendaman Giberelin (GA3) dan pengamplasan untuk memecahkan masa dormansi dari benih aren tersebut.

\section{Persiapan Tempat Penelitian}

Tempat pelaksanaan penelitian dibersihkan dari gulma. Pembuatan naungan dibuat dengan menggunakan paranet 50\%. Naungan dilapisi plastik bening pada bagian atap/atas.

\section{Persiapan Media Tanam}

Media tanam yang digunakan adalah campuran subsoil dari tanah ultisol dan arang tempurung kelapa sesuai dengan perlakuan dengan menggunakan perbandingan v/v. Sebelum dilakukan pencampuran media yang sesuai dengan perlakuan, tanah subsoil dan arang tempurung kelapa dilakukan sterilisasi untuk menghindari adanya jamur dan bakteri yang akan menghambat pertumbuhan FMA. Sterilisasi dilakukan dengan metode autoclave dengan tekanan $0,1 \mathrm{mpa}$ dan suhu $121^{\circ} \mathrm{C}$ selama \pm 1 jam. Setelah dilakukan sterilisasi, media dicampur sesuai dengan perlakuan kemudian dimasukkan kedalam polybag yang telah disiapkan dengan berukuran $14 \mathrm{~cm} \times 22 \mathrm{~cm}$.

\section{Pemindahan Semai dan Pemberian Perlakuan FMA}

Pemindahan semai aren dari bak kecambah ke polybag dilakukan berbarengan dengan pemberian perlakuan dosis inokulum FMA yang telah ditentukan. Inokulum FMA diusahakan mengenai akar aren agar FMA dapat berinteraksi dengan akar bibit aren.

\section{Pemeliharaan}

Pemeliharaan bibit meliputi kegiatan penyiraman, penyiangan gulma, dan pengendalian hama dan penyakit.

\section{Pertambahan Tinggi Bibit (cm)}

Pengukuran tinggi bibit dilakukan mulai dari leher akar sampai titik tumbuh. Pengukuran tinggi dengan mengukur pada batang bibit $(1 \mathrm{~cm}$ dari leher akar) hingga titik tumbuh tertinggi sehingga batas pengukuran tidak berubah. 


\section{Pertambahan Diameter Batang (cm)}

Pengukuran diameter batang bibit aren diukur pada batang utama $(1 \mathrm{~cm}$ dari leher akar). Pengukuran pertama diberi tanda agar pada pengukuran diameter berikutnya dilakukan pada tempat yang sama.

\section{Pertambahan Jumlah Daun (helai)}

Daun yang dihitung adalah daun yang telah membuka sempurna. Pengamatan pertambahan jumlah daun pertama dilakukan dua minggu setelah tanam.

\section{Berat Kering Tajuk (gram)}

Data berat kering tajuk dilakukan diakhir penelitian dengan menggunakan sampel destruktif. Sampel yang diambil berupa bagian mulai dari leher akar sampai ujung tajuk (daun dan batang). Sampel tersebut kemudian dilakukan pengovenan dengan suhu $103 \pm 2{ }^{\circ} \mathrm{C}$ selama 12 jam sampai mendapatkan berat kering konstan.

\section{Berat Kering Akar (gram)}

Data berat kering akar didapatkan dari sampel destruktif berupa akar bibit yang telah dibersihkan pada saat akhir penelitian. Bagian akar tersebut kemudian dilakukan pengovenan sampai berat kering konstan dengan suhu $103 \pm 2{ }^{\circ} \mathrm{C}$ selama 12 jam.

\section{Rasio Pucuk Akar}

Rasio pucuk akar diperoleh dari data selisih antara berat kering tajuk dengan berat kering akar dengan rumus sebagai berikut :

$$
\text { Rasio Pucuk Akar }=\frac{\text { Berat Kering Tajuk }}{\text { Berat Kering Akar }}
$$

\section{Persen Infeksi Akar (\%)}

Persen akar terinfeksi dilakukan setelah pewarnaan akar. Persen akar terinfeksi dihitung dengan rumus :

Persen akar terinfeksi $=\frac{\text { jumlah } \text { akar terinfeksi }}{\text { jumlah contoh } \text { akar }} \times 100 \%$

\section{HASIL DAN LUARAN YANG DICAPAI}

Hasil sidik ragam pengaruh pemberian inokulum FMA dan arang tempurung kelapa terhadap pertumbuhan bibit aren di persemaian ditunjukkan pada Tabel 1. 
Tabel 1 Rekapitulasi hasil analisis ragam data pertumbuhan Aren yang diberikan perlakuan Arang Tempurung Kelapa dan Mikoriza

\begin{tabular}{lccccc}
\hline \multicolumn{1}{c}{ Peubah } & $\begin{array}{c}\text { Arang } \\
(\mathrm{A})\end{array}$ & $\begin{array}{c}\text { Mikoriza } \\
(\mathrm{M})\end{array}$ & $\begin{array}{c}\text { Interaksi } \\
(\text { PxM })\end{array}$ & KK & R2 \\
\hline 1. Tinggi Tanaman $(\mathrm{cm})$ & tn & tn & tn & 27.51 & 0.46 \\
2. Diameter Tanaman $(\mathrm{cm})$ & tn & tn & tn & 34.36 & 0.21 \\
3. Jumlah Daun (helai) & $*$ & tn & tn & 23.21 & 0.48 \\
4. Berat Kering Tajuk $(\mathrm{g})$ & tn & tn & tn & 22.87 & 0.34 \\
5. Berat Kering Akar $(\mathrm{g})$ & tn & tn & tn & 15.22 & 0.36 \\
6. Rasio Pucuk Akar $(\mathrm{g})$ & tn & tn & tn & 11.81 & 0.28 \\
7. Persen Infeksi Akar $(\%)$ & tn & $* *$ & tn & 20.78 & 0.92 \\
\hline
\end{tabular}

(tn) : tidak berbeda nyata $\left({ }^{*}\right)$ : berbeda nyata pa da taraf uji $5 \%,\left({ }^{* *}\right)$ : berbeda sangat nyata pada taraf uji $1 \% ; \mathrm{KK}:$ koefisien keragam an; $\mathrm{R} 2: \mathrm{R}$ kuadrat; $(\mathrm{t})$ : hasil traform asi akar $(\mathrm{x}+0.5) ;$ MST: minggu setelah tanam.

Tabel 1 menunjukkan bahwa arang tempurung kelapa memberikan pengaruh yang nyata terhadap pertambahan pertambahan jumlah daun, namun tidak memberikan pengaruh yang nyata pada pertambahan diameter dan pertambahan tinggi tanaman. Pemberian mikoriza memberikan pengaruh yang sangat nyata pada variabel persen infeksi akar dan tidak memberikan pengaruh yang nyata pada variabel pengamatan lainnya. Begitu juga dengan interaksi antara perlakuan arang tempurung kelapa dan mikoriza tidak memberikan pengaruh yang nyata pada semua variabel pengamatan.

Berdasarkan analisis ragam yang menunjukkan pengaruh pada semua parameter, dilanjutkan dengan melalukan uji DMRT untuk melihat perbedaan masing-masing taraf perlakuan. Hasil analisis pengaruh pemberian arang tempurung kelapa terhadap pertambahan tinggi, diameter, jumlah daun dapat dilihat pada Tabel 2.

Tabel 2. Pengaruh berbagai dosis Arang Tempurung Kelapa terhadap pertumbuhan tanaman Aren

\begin{tabular}{lcccccccc}
\hline Parameter & $\begin{array}{c}\text { Tinggi } \\
(\mathrm{cm})\end{array}$ & $\begin{array}{c}\text { Diameter } \\
(\mathrm{cm})\end{array}$ & $\begin{array}{c}\text { Jml Daun } \\
\text { (helai) }\end{array}$ & $\begin{array}{c}\text { BK Tajuk } \\
(\mathrm{g})\end{array}$ & $\begin{array}{c}\text { BK Akar } \\
(\mathrm{g})\end{array}$ & $\begin{array}{c}\text { Rasio } \\
\text { Pucuk } \\
\text { Akar }\end{array}$ & $\begin{array}{c}\text { Persen } \\
\text { Infeksi } \\
(\%)\end{array}$ \\
\hline $\mathrm{A} 0(0 \%)$ & $8.27 \mathrm{a}$ & $0.67 \mathrm{a}$ & $2.06 \mathrm{~b}$ & $2.84 \mathrm{a}$ & $1.58 \mathrm{a}$ & $1.10 \mathrm{ab}$ & $57.5 \mathrm{a}$ \\
$\mathrm{A} 1(10 \%)$ & $9.23 \mathrm{a}$ & $0.61 \mathrm{a}$ & $2.56 \mathrm{a}$ & $3.29 \mathrm{a}$ & $1.52 \mathrm{a}$ & $1.04 \mathrm{~b}$ & $62.5 \mathrm{a}$ \\
$\mathrm{A} 2(20 \%)$ & $9.53 \mathrm{a}$ & $0.60 \mathrm{a}$ & $2.01 \mathrm{~b}$ & $2.86 \mathrm{a}$ & $1.72 \mathrm{a}$ & $1.17 \mathrm{a}$ & $61.7 \mathrm{a}$ \\
\hline
\end{tabular}

Keterangan: angka-angka yang diikutioleh hurufyang sama pada kolom yang sama menunjukkan tidak berbeda nyata berdasarkan uji DMRT pada taraf $5 \%$

Berdasarkan Tabel 2 dapat dilihat bahwa pemberian dosis arang tempurung kelapa berbeda nyata terhadap perlakuan kontrol pada parameter pertambahan pertambahan jumlah daun. Pengaruh tunggal arang tempurung kelapa terlihat pada pemberian arang tempurung kelapa dosis $10 \%$ yang menunjukkan nilai lebih tinggi pada parameter pertambahan jumlah daun. Perlakuan arang tempurung 
kelapa $0 \%, 10 \%, 20 \%$ pada parameter pertambahan jumlah daun berbeda nyata dengan perlakuan kontrol. Pada parameter pertambahan diameter dan tinggi tanaman tidak memberikan perbedaan yang nyata untuk semua perlakuan.

Parameter berat kering tajuk, persen infeksi dan berat kering akar menunjukkan perbedaan tidak nyata pada semua perlakuan arang tempurung kelapa. Pada parameter rasio pucuk akar pemberian arang tempurung kelapa dosis $20 \%$ yang menunjukkan nilai lebih tinggi dibandingkan dengan perlakuan $10 \%$, namun tidak berbeda nyata dengan tanpa diberikan arang.

Indikator yang umumnya digunakan sebagai suatu yang menunjukan kualitas pertumbuhan suatu tanaman adalah total berat kering (BKT akar dan BKA) karena berat kerinrg tajuk tanaman dapat menggambarkan efisiensi proses fisiologis di dalam tanaman. Nilai biomassa suatu tanaman juga dapat digambarkan pada berat kering total tanaman. Hal tersebut ditunjukan adanya kolerasi yang positif antar BKT dan Biomassa. Semakin besar nilai BKT maka semakin besar nilai biomassanya. Semakin besar nilai biomassa suatu tanaman akan berpengaruh kepada petumbuhan dari tanaman tersebut. Hal tersebut terjadi karena dalam proses keberlangsungan hidupnya, hasil fotosintesis tanaman digunakan dalam membentuk biomassa yang ditandai dengan pertambahan tinggi, pertambahan berat dan pertambahan ukuran yang lainnya yang dalam hal ini dapat dinyatakan dalam bentuk kuantitatif (Sitompul \& Guritno 1995). Variabel berat kering pucuk sangat berhubungan erat dengan variabel diameter tanaman, tinggi tanaman, jumlah daun tanaman, dimana semakin besar variabel tersebut akan semakin besar pula berat kering pucuknya dan tentunya hal ini juga dapat menunjukan performa pertumbuhan dari tanaman tersebut.

Dalam penelitian ini kebutuhan hara untuk pertumbuhan tanaman ditopang juga oleh keberadaan bahan organik seperti arang tempurung kelapa. Arang tempurung kelapa mengandung unsur-unsur hara yang dibutuhkan oleh tanaman seperti Posfor, Nitrogen dan Kalium. Selain itu juga mengandung C-organik dan Magnesium yang sangat tinggi yang dapat memenuhi kebutuhan hara tanaman Aren. Dengan karakteristik tersebut, arang tempurung kelapa akan memperbaiki sifat - sifat tanah sehingga akan menghasilkan bibit yang berkualitas tinggi. Leiwakabessy (2003) menyatakan bahwa fosfat merupakan hara yang sangat dibutuhkan dalam proses fotosintesis, metabolisme asam amino, lemak, dan sulfur, glikolisis, oksidasi biologis, pembentukan karbohidrat dan dan senyawa lainnya, , dan beberapa reaksi lainnya.

Penambahan arang tempurung kelapa pada media tanam sangat menguntung tanaman karena, dengan adanya penambahan arang tersebut dapat memperbaiki sifat fisik tanah yaitu dalam hal ini adalah porositas dan aerasi yang akan memudahkan akar tanaman dapat berkembang sehingga dapat menjangkau unsur hara di dalam tanah. Selain itu arang tempurung kelapa ini juga berfungsi sebagai pengikat hara yang nantinya akan digunakan tanaman apabila kekurangan unsur hara yang akan dilepas secara perlahan sesuai dengan kebutuhan tanaman 
(Komarayati et al. 2003). Sehingga tanaman tidak akan kekurangan hara dan keracunan hara. Hasil pengamatan menunjukkan aren di media yang ditambahkan arang tempurung kelapa memiliki pertumbuhan yang lebih baik daripada di media tanpa arang tempurung kelapa dilihat dari rata- rata nya (kontrol).

Parameter rasio pucuk akar menunjukan perbedaan yang tidak nyata pada semua perlakuan arang tempurung kelapa. Berdasarkan nilai rata - rata pemberian arang sebanyak $20 \%$ memberikan nilai rasio pucuk akar yang lebih tinggi dibandingkan perlakuan lainnya. Rasio pucuk akar yang memiliki nilai yang tinggi menggambarkan pertumbuhan area pucuk yang lebih tinggi dibandingkan pada area akar. Harris ( 1992) menyatakan bahwa nilai kisaran 1-5 merupakan nilai rasio pucuk dan akar terbaik. Sehingga dapat dikatakan bahwa tanaman aren yang diberi perlakuan arang tempurung kelapa dapat menghasilkan kualitas bibit yang baik. Rasio pucuk akar yang memiliki nilai yang tinggi adalah indikator yang menunjukan bahwa media tanam yang menjadi tempat tumbuhnya adalah media yang subur dengan ketersediaan air yang cukup (Frianto, 2007), hal tersebut terjadi karena arang tempurung kelapa dapat menambah hara dan juga memperbaiki sifat fisik tanah sehingga tanah dapat mengikat air untuk kebutuhan pertumbuhan Aren.

Berdasarkan analisis ragam yang menunjukkan pengaruh pada semua parameter, dilanjutkan dengan melalukan uji DMRT untuk melihat perbedaan masing-masing taraf perlakuan. Hasil analisis pengaruh pemberian mikoriza terhadap pertambahan tinggi, diameter, jumlah daun dapat dilihat pada Tabel 3.

Tabel 3. Pengaruh berbagai mikoriza terhadap pertumbuhan tanaman Aren

\begin{tabular}{|c|c|c|c|c|c|c|c|}
\hline Parameter & $\begin{array}{l}\text { Tinggi } \\
(\mathrm{cm})\end{array}$ & $\begin{array}{l}\text { Diameter } \\
(\mathrm{cm})\end{array}$ & $\begin{array}{l}\text { Jlm Daun } \\
\text { (helai) }\end{array}$ & $\begin{array}{l}\text { BK Tajuk } \\
\text { (g) }\end{array}$ & $\begin{array}{c}\text { BK Akar } \\
\text { (g) }\end{array}$ & $\begin{array}{c}\text { Rasio } \\
\text { Pucuk } \\
\text { Akar }\end{array}$ & $\begin{array}{c}\text { Persen Infeksi } \\
(\%)\end{array}$ \\
\hline M0 (0 g) & $7.88 \mathrm{a}$ & 0.63 a & $2.33 \mathrm{ab}$ & $2.63 \mathrm{a}$ & $1.55 \mathrm{a}$ & $1.12 \mathrm{a}$ & $0.00 \mathrm{c}$ \\
\hline M1 (5 g) & $9.78 \mathrm{a}$ & $0.57 \quad \mathrm{a}$ & $1.82 \mathrm{~b}$ & 3.14 a & $1.63 \mathrm{a}$ & $1.11 \mathrm{a}$ & $73.3 \mathrm{~b}$ \\
\hline M2 (10 g) & $8.80 \mathrm{a}$ & $0.68 \mathrm{~b}$ & $2.37 \mathrm{a}$ & $2.96 \mathrm{a}$ & $1.57 \mathrm{a}$ & $1.08 \mathrm{a}$ & $81.1 \mathrm{ab}$ \\
\hline M3 (15 g) & $9.60 \mathrm{a}$ & $0.66 \mathrm{~b}$ & $2.30 \mathrm{ab}$ & $3.26 \mathrm{a}$ & $1.67 \mathrm{a}$ & $1.10 \mathrm{a}$ & $87.8 \mathrm{a}$ \\
\hline
\end{tabular}

Keterangan: angka-angka yang diikuti oleh huruf yang sama pada kolom yang sama menunjukkan tidak berbeda nyata berdasarkan uji DMRT pada taraf $5 \%$

Pada variabel persen infeksi akar terlihat bahwa semakin banyak inokulasi mikoriza yang diberikan maka akan semakin banyak juga persen infeksi akarnya, dimana dalam hal ini pemberian inokulasi $15 \mathrm{~g}$ dan $10 \mathrm{~g}$ memberikan persen infeksi akar yang lebih besar dibandikan dengan perlakuan lainnya. Dan perlakuan kontrol sama sekali tidak terjadi adanya persen infeksi akar. Hal tersebut diduga karena adanya penambahan arang tempurung kelapa didalam tanah dapat meningkatkan persen infeksi mikoriza yaitu dengan menyediakan habitat yang sesuai untuk perkembangan perkembangan hifa melalui adanya perbaikan pada pori mikro (Warnock et al., 2007). Smith \& Read (1997) juga menyatakan bahwa persen infeksi akar bergantung pada tanaman inang dan spesies mikoriza, dan juga sering dihubungkan adaptasi tanaman dan pertumbuhan akar. 
Variabel persen infeksi tersebut hanya berpengaruh pada variabel jumlah daun, hal ini diduga karena infeksi mikioriza belum berkembang secara sempurna. Lamanya penelitian yang hanya 3 bulan juga diduga menyebabkan peran dari mikoriza belum terlihat. Hal tersebut didukung oleh pernyataan Pulungan (2017) dimana inokulasi mikoriza selama 18 minggu setelah tanam belum mampu menginfeksi akar bibit Jabon merah secara optimal dan pengamatan yang relatif pendek menyebabkan respon bibit Jabon belum terlihat jelas. Hal tersebut terlihat dari perkembangan infeksi hanya baru berbentuk hifa dan belum terbentuknya spora. Menurut Sari et al. (2016) mikoriza dapat meningkatkan efisiensi penerimaan nutrisi oleh tanaman sangat bergantung dari 3 proses, yaitu pengambilan nutrisi oleh misileum dari dalam tanah, traslokasi hara dalam hifa ke struktur intraradikal mikoriza dari dalam tanah dan trasfer hara dari mikoriza ke tanaman melewati permukaan yang kompleks diantara simbion. Dapat terlihat bahwa dengan tidak sempurnanya perkembangan dari mikoriza, maka akan menurunkan efisiensi dari mikoriza yang akibatnya akan menghambat penerimaan nutrisi oleh tanaman.

\section{KESIMPULAN DAN SARAN}

\section{Kesimpulan}

1. Inokulasi mikoriza dan dosis arang tempurung kelapa tidak berinteraksi secara nyata terhadap semua variabel pertumbuhan tanaman Aren.

2. Pemberian dosis arang tempurung kelapa memberikan pengaruh yang sangat nyata terhadap pertambahan jumlah daun namun tidak memberikan pengaruh yang nyata pada variabel pengamatan lainnya. Pemberian mikoriza memberika pengaruh yang sangat nyata pada variabel persen infeksi akar, namun tidak memberikan pengaruh yang nyata pada variabel pengamatan lainnya.

3. Pemberian dosis arang tempurung kelapa $10 \%$ dan dosis mikoriza $10 \mathrm{~g}$ menunjukkan pengaruh yang lebih baik terhadap pertumbuhan tanaman Aren.

\section{Saran}

Berdasarakan penelitian yang telah dilakukan, dapat disarankan yaitu dosis arang tempurung kelapa dapat diberikan sebanyak $10 \%$ dan mikoriza sebanyak $10 \mathrm{~g}$ untuk memacu pertumbuhan tanaman Aren juga dapat diberikan secara berkala setiap tahunnya agar tanaman tumbuh lebih baik. Dan perlu adanya pengamatan yang lebih lama lagi yaitu lebih dari 4 bulan agar pengaruh pemberian mikoriza dan dosis arang tempurung kelapa dapat terlihat nyata.

\section{UCAPAN TERIMAKASIH}

DIPA-PNBP Fakultas Kehutanan Skema Dasar Unggulan Fakultas Nomor : SP DIPA-023.17.2.677565/2020 Tanggal 27 Desember 2019, dan seusai dengan Surat Perjanjian Kontrak Penelitian Nomor : 423/UN21.18/PG/SPK/2020, Tanggal 20 April 2020 


\section{DAFTAR PUSTAKA}

Akuba R.H. 2004. Profil Aren. Pengembangan Tanaman Aren. Balai Penelitian Tanaman Kelapa dan Palma Lain. Tondano. Prosiding Seminar Nasional Aren. 9 Juni.

Dewi I.R. 2007. Peran, prospek, dan kendala dalam pemanfaatan endomikoriza. Makalah.Fakultas pertanian, Universitas Padjadjaran.

Ditjen Perkebunan. 2004. Pengembangan Tanaman Aren di Indonesia. Balai Penelitian Tanaman Kelapa dan palma Lain. Tondano 9 Juni 2004. Prosiding Seminar Nasional Aren.

Effendi D.S. 2009. Aren, Sumber Energi Alternatif. Warta Penelitian dan Pengembangan Pertanian. 31(2):1-3.

Frianto. 2007. Aplikasi arang kompos pada media sapih dan pengaruhnya terhadap pertumbuhan Hopea odorata di persemaian. Jurnal Penelitian Hasil Hutan dan Konservasi Alam (7) 3: 281-282.

Harris RW. 1992. Root-shoot ratio. Journal of Arboriculture. 8(1): 39-42.

Komarayati S, Pari G dan Gusmailina. 2003. Pengembangan Penngunaan Arang untuk Rehabilitasi Lahan dalam Buletin Penelitian dan Pengembangan Kehutanan 4:1. Jakarta: Badan Penelitian dan Pengembangan Kehutanan.

Lempang M. 2012. Pohon Aren Dan Manfaat Produksinya. Balai Penelitian Kehutanan. Makassar.

Leiwakabessy F. M. 2003. Kesuburan Tanah. Diktat Kuliah Kesuburan Tanah Fakultas Pertanian Institut Pertanian Bogor, Bogor

Manaroinsong, E. Maliangkay, R.B. \& Mantana, Y.R. 2006. Observasi Produksi Nira Aren di Kecamatan Langowan, Kabupaten Minahasa Induk, Propinsi Sulawesi Utara. Buletin Palma No. 31. Pusat Penelitian dan Pengembangan Tanaman Perkebunan. Bogor.

Nurmalasari D. 2009. Efektivitas Mycofer terhadap Tanaman Kehutanan, Pertanian, Perkebunan, Bioremediasi, dan Pakan Hijau Ternak (Kajian Pustaka). Skripsi. Departemen Silvikultur Fakultas kehutanan Institut Pertanian Bogor, Bogor.

Pulungan I.A. 2017. Pengaruh inokulasi fungi mikoriza arbuskula (FMA) terhadap pertumbuhan bibit jabon (Anthochepalus macrophyllus ROXB Havii.). Skripsi. Fakultas Kehutanan. Universitas Jambi.

Rindengan B dan E. Manaroinsong. 2009. Aren. Tanaman Perkebunan Penghasil Bahan Bakar Nabati (BBN). Pusat penelitian dan Pengembangan Perkebunan.

Sari A, ZA Noli dan Suwiren. 2016. Pertumbuhan bibit Surian (Toona sinensis) yang diinokulasi mikoriza pada media tanam tanah ultisol. Jurnal AL-Kauniyah Jurnal Biologi 9(1):1-9.

Setiawan A. 2014. Eksplorasi Anakan Alam Aren (Arenga Pinnata Merr) Di Temanggung Dan Cara Penanganannya. Balai Besar Penelitian Bioteknologi dan Pemuliaan Tanaman Hutan. Yogyakarta. 
Sitompul SM, Guritmo B. 1995. Analisis Pertumbuhan Tanaman. Yogyakarta: Gajah Mada University Press.

Soemeinaboedhy IN, Tejowulan RS. 2007. Pemanfaatan berbagai macam arang sebagai sumber unsur $\mathrm{P}$ dan $\mathrm{K}$ serta sebagai pembenah tanah. Jurnal Agroteksos. 17(2): 115-121.

Subekti A, D Permana dan TS Wahyuni. 2017. Pengaruh pupuk kandang kotoran ayam terhadap pertumbuhan dan hasil tanaman talas lokal (Colocasia esculenta L.S hott) pada Ultisol di Kalimantan Barat. Prosiding Seminar Hasil Penelitian Tanaman Aneka Kacang dan Umbi. 684-693.

Smith SE dan Read DJ. 1997. Mycorrhizal Symbiosis. Second Eds. San Diego California. Academic Press: Harcourt Barace and Company Publ.

Warnock DD, Lehmann J, Kuyper TW, Rillig MC. 2007. Mycorrhizal responses to biochar in soil - concepts and mechanism. Plant Soil 300: 9-20. 